\title{
STUDENTS' PERCEPTION TOWARDS INTERPROFESSIONAL EDUCATION (IPE) USING TEAM-BASED LEARNING (TBL)
}

\author{
Warjidin Aliyanto ${ }^{1}$, Retno Puji Hastuti², Dwita Oktaria ${ }^{3 *}$ \\ ${ }^{1}$ Program Studi Keperawatan, Politeknik Kesehatan Tanjung Karang, Bandar Lampung- INDONESIA \\ ${ }^{2}$ Program Studi Kebidanan, Politeknik Kesehatan Tanjung Karang, Bandar Lampung- INDONESIA \\ ${ }^{3}$ Bagian Pendidikan Kedokteran, Fakultas Kedokteran Universitas Lampung, Bandar Lampung - INDONESIA
}

Submitted: 03 Jan 2021; Final Revision from Authors: 12 Apr 2021; Accepted: 12 Apr 2021

\begin{abstract}
Background: The healthcare system consists of collaborations from multiple related professions to provide superior services for patients. The ability to cooperate in an interprofessional environment should be introduced at an early stage for healthcare students in the workplace amongst various disciplines. Interprofessional education (IPE), is an innovation where a group of students from several health professions conduct learning together, to create effective collaboration in order to improve the quality of health services. One of the active learning methods that can be used is Team-Based Learning (TBL). This study aims to elaborate students' perception of IPE learning using TBL as the active learning method.
\end{abstract}

Method: The mixed - method is applied in this research. 162 students from four applied undergraduate study programs at the Tanjungkarang Health Polytechnic are sampled. 26 groups consisting of 6 - 7 students from various study programs are divided from the sample. Data was collected using sli.do at the end of TBL session.

Results: Student perceptions included: entertaining learning processes, higher knowledge absorptions, improved interprofessional teamwork and communication and better critical thinking skills. Refining teacher competency, increasing profession diversity in the discussions, increasing session duration and higher topic complexity are important factors to ameliorate further IPE learning using TBL. 81\% of students had a positive (excellent and good) response in regards to IPE learning using the TBL.

Conclusion: Students possess a positive perception and increased benefits for IPE learning using TBL. TBL may be one of the prospective methods to convey IPE concepts.

Keywords: interprofessional education, team-based learning, collaboration

\begin{abstract}
ABSTRAK
Latar belakang: Sistem pelayanan kesehatan terdiri dari kolaborasi berbagai profesi untuk memberikan pelayanan yang terbaik bagi pasien. Kemampuan bekerjasama secara interprofesional harus dilatih sejak dini agar mahasiswa dari berbagai profesi kesehatan memiliki pengetahuan dan pengalaman cara bekerjasama dengan profesi lain sebelum mereka terjun ke dunia kerja. Interprofessional Education (IPE), merupakan inovasi dalam konsep pendidikan kesehatan dimana sekelompok mahasiswa dari berbagai profesi kesehatan melakukan pembelajaran bersama, untuk menciptakan kolaborasi efektif agar dapat meningkatkan kualitas pelayanan kesehatan. Salah satu metode pembelajaran aktif yang dapat digunakan adalah Team-Based Learning (TBL). Penelitian bertujuan untuk mengetahui persepsi mahasiswa mengenai pembelajaran IPE yang dilakukan dengan TBL.
\end{abstract}

*corresponding author, contact: dwitaoktaria@gmail.com 
Metode: Penelitian ini menggunakan mixed - method. Sampel penelitian sebanyak 162 mahasiswa dari empat program studi sarjana terapan di Politeknik Kesehatan Tanjungkarang. Sampel dibagi ke dalam 26 kelompok yang terdiri dari $6-7$ orang mahasiswa dari berbagai program studi. Di akhir sesi TBL dilakukan pengumpulan data menggunakan aplikasi sli.do.

Hasil: Persepsi mahasiswa antara lain proses pembelajaran menyenangkan, menambah pengetahuan, meningkatkan kerjasama tim serta komunikasi antarprofesi dan melatih kemampuan berpikir kritis. Adapun masukan untuk pelaksanaan di masa yang akan datang antara lain peningkatan kompetensi pengajar, menambah perlibatan jumlah profesi, meningkatkan durasi waktu dan membuat diskusi yang lebih kompleks. Didapatkan hasil 81\% mahasiswa memiliki respon positif (sangat baik dan baik) mengenai pembelajaran IPE dengan metode TBL.

Kesimpulan: Mahasiswa memiliki persepsi positif untuk pembelajaran IPE dengan metode TBL. Metode TBL dapat menjadi salah satu alternatif metode pembelajaran untuk menyampaikan materi dan konsep dari IPE.

Kata kunci: interprofessional education, kolaborasi, team-based learning

\section{PRACTICE POINTS}

- Students have a positive perception for IPE learning using the TBL.

- TBL may be one of the prospective methods to convey IPE concepts.

\section{PENDAHULUAN}

Sistem pelayanan kesehatan merupakan suatu sistem yang sangat kompleks. Sistem ini terdiri dari kolaborasi berbagai profesi untuk dapat memberikan pelayanan kesehatan yang terbaik bagi pasien. Namun masalah yang sering terjadi antara lain adanya tumpang tindih pelayanan, kurangnya komunikasi dan kerjasama tim yang terdiri dari berbagai profesi. Tumpang tindih kompetensi terjadi akibat belum adanya batasan peran yang jelas dalam memberikan pelayanan kesehatan sehingga memicu ketegangan dan menghambat kerjasama antar tenaga kesehatan. ${ }^{1}$ Kendala yang sering ditemui pada pelayanan kesehatan yaitu minimnya komunikasi dan kerjasama di dalam tim kesehatan sehingga menghambat dalam membuat keputusan untuk pasien. Dampaknya antara lain pelayanan kesehatan menjadi tidak efektif dan efisien, dan menyebabkan timbulnya ketidakpuasan terhadap kualitas pelayanan yang diberikan. ${ }^{2}$ Oleh karena itu, pada tahun 2010, $\mathrm{WHO}^{3}$ mencetuskan Interprofessional Education (IPE), suatu inovasi dalam konsep pendidikan kesehatan dimana sekelompok mahasiswa dari beberapa profesi kesehatan yang berbeda melakukan pembelajaran bersama dalam periode tertentu, untuk menciptakan kolaborasi efektif dan pada akhirnya meningkatkan kualitas pelayanan kesehatan. Kemampuan bekerjasama secara interprofesional tidak muncul begitu saja. Hal ini harus dilatih sejak tahap perkuliahan agar mahasiswa dari berbagai profesi kesehatan memiliki pengetahuan dan pengalaman cara bekerjasama dengan profesi lain sebelum mereka terjun ke dunia kerja. ${ }^{4}$

Konsep IPE harus ditempatkan dalam kurikulum pendidikan tinggi kesehatan dan diaplikasikan dalam bentuk praktik terpadu di masyarakat. Sistem kesehatan dan sistem pendidikan tidak bisa berdiri sendiri. Sistem pendidikan akan memberikan input pada sistem kesehatan sebagai pengguna lulusan, kualitas tenaga kesehatan yang dihasilkan akan mempengaruhi baik tidaknya pelayanan kesehatan, sebaliknya sistem pendidikan akan dipengaruhi oleh sistem kesehatan misalnya kurikulum pendidikan tinggi kesehatan akan dipengaruhi oleh kebutuhan 
kesehatan masyarakat sehingga kompetensi lulusan harus menyesuaikan dengan kebutuhan kesehatan dan kebijakan di bidang kesehatan. ${ }^{5}$ Saat ini penerapan IPE di beberapa institusi pendidikan tinggi kesehatan di dunia masih terbatas, hasil survey pada universitas di 42 negara menemukan bahwa baru sekitar 24,6\% yang menerapkan kurikulum IPE pada tahap akademik. Di Indonesia penerapan IPE di pendidikan tinggi kesehatan juga masih minim, dan diperlukan sosialisasi metode pembelajaran IPE di institusi pendidikan tinggi kesehatan sebagai penyedia calon tenaga kesehatan. ${ }^{3}$

Politeknik Kesehatan Tanjungkarang yang selanjutnya disebut Poltekkes Tanjungkarang sebelumnya telah melaksanakan pembelajaran klinik yang melibatkan seluruh jurusan/prodi melalui kegiatan Praktik Kerja Lapangan (PKL) Terpadu. Mahasiswa dari delapan jurusan melaksanakan praktik kesehatan komunitas bersama di suatu wilayah. Namun pada saat itu proses pembelajaran belum menerapkan pendekatan interprofesional. Tujuan pembelajaran masih merupakan capaian pembelajaran mata kuliah dari masing-masing program studi. Kegiatan PKL terpadu sejak 2014 tidak dilaksanakan lagi karena dinilai kurang efektif dan efisien oleh beberapa jurusan sehingga perlu dilakukan evaluasi. Pada tahun 2019, Poltekkes Tanjungkarang memulai dengan sebuah proyek penelitian untuk mencari suatu rancangan pembelajaran IPE yang sesuai untuk diterapkan dalam pembelajaran IPE dengan jumlah peserta didik yang besar karena melibatkan dosen dan mahasiswa dari beberapa jurusan/prodi yang berbeda.

Model pembelajaran IPE tergantung pada tingkat kedalaman dan integrasi pembelajaran di kelas dan wahana praktik. Untuk pembelajaran di kelas terdapat dua model pembelajaran, yaitu model pembelajaran IPE bersama antar profesi di dalam kelas yang sama dan model pembelajaran yang memandu mahasiswa untuk mencapai kompetensi kerjasama antar profesi. ${ }^{5}$ Pembelajaran IPE harus menerapkan metode pembelajaran reflektif dimana mahasiswa lebih dari satu profesi saling berinteraksi sehingga memiliki pengalaman berinteraksi dan bekerja sama. ${ }^{6}$ Pada pembelajaran IPE, mahasiswa tidak hanya dituntut untuk menguasai kemampuan substansi atau teknis, tetapi juga harus memahami karakter, potensi, dan permasalahan yang ada di lapangan. Oleh karena itu diperlukan proses pembelajaran aktif yang dapat mendukung tantangan terlatihnya kemampuan hard skill dan soft skill mahasiswa. Salah satu rancangan pembelajaran dimaksud adalah rancangan TeamBased Learning (TBL). Michaelsen dan Sweet ${ }^{7}$ mendefinisikan "Team Based Learning (TBL) is a collection of practices that support one another for powerful instructional effect." TBL merupakan salah satu metode pembelajaran aktif. Pembelajaran ini memiliki empat karakteristik antara lain: 1) penekanan pada proses pembelajaran bukan pada penyampaian informasi oleh pengajar. TBL mengembangkan keterampilan pemikiran analitis dan kritis mahasiswa terhadap topik atau permasalahan yang dibahas, 2) mahasiswa tidak hanya mendengarkan secara pasif tetapi mengerjakan sesuatu yang berkaitan dengan materi kuliah, 3) rancangan pembelajaran TBL menekankan pada eksplorasi nilai-nilai dan sikap berkenaan dengan materi kuliah, mahasiswa lebih banyak dituntut untuk berpikir kritis, menganalisis dan melakukan evaluasi, dan 4) umpan balik yang cepat pada proses pembelajaran. ${ }^{7}$ Karakteristik dari TBL ini dapat digunakan untuk membangun budaya kolegialitas di antara mahasiswa profesi kesehatan. Selain itu, sesi TBL menyediakan kesempatan untuk memberi contoh kerjasama interprofesional kepada mahasiswa, dimana pengajar dari berbagai profesi kesehatan bekerja sebagai tim interdisipliner untuk memberi pengajaran IPE kepada mahasiswa. ${ }^{8}$

Beberapa studi menyebutkan metode pembelajaran interprofesional dengan TBL menjadi pilihan untuk memperkenalkan konsep dan nilai-nilai IPE kepada mahasiswa dari berbagai profesi. Mahasiswa akan belajar menghargai interaksi dengan mahasiswa dari profesi lain, memiliki kesempatan untuk memecahkan masalah secara bersama-sama dan belajar perspektifberbeda dari kasus pasien. ${ }^{8} \mathrm{TBL}$ juga meningkatkan keterlibatan mahasiswa dalam proses pembelajaran melalui proses pembelajaran aktif, bekerjasama dengan teman dalam satu kelompok untuk memecahkan masalah yang disajikan. ${ }^{9}$ Berdasarkan latar belakang tersebut, peneliti tertarik untuk mengetahui persepsi mahasiswa mengenai Interprofessional Education (IPE) yang dilakukan dengan Team-Based Learning (TBL). 


\section{METODE}

Penelitian dilakukan pada bulan September 2019 dengan sampel penelitian sebanyak 162 mahasiswa dari empat program studi profesi yang berbeda, yaitu keperawatan, kebidanan, analis kesehatan dan kesehatan lingkungan. Penelitian ini menggunakan mixed - method. Pengumpulan data menggunakan aplikasi berbasis web sli.do dengan mengajukan pertanyaan terbuka dan penilaian menggunakan skala rating.

Pelaksanaan IPE dengan TBL ini dilakukan sebanyak 4 sesi dengan 4 materi berbeda yaitu nilai dan etika profesi, peran dan tanggung jawab profesi, komunikasi antar profesi dan kerjasama dalam tim.
Waktu pelaksanaan setiap sesi kurang lebih 3 jam. Setiap sesi akan dipimpin oleh seorang staf pengajar yang berperan sebagai fasilitator. Staf pengajar ini merupakan penyusun dari materi modul IPE dan telah mengikuti pelatihan TBL.

Setiap sesi proses pembelajaran IPE dengan TBL dibagi menjadi tiga tahap, yaitu tahap persiapan, tahap penilaian kesiapan (readiness assurance) dan tahap aplikasi. Adapun tahapannya dapat dilihat pada Gambar 1. Beberapa hari sebelum sesi TBL, mahasiswa terlebih dahulu ditugaskan untuk membaca sumber belajar yaitu modul IPE sesuai dengan materi yang telah dijadwalkan untuk setiap sesi. Ini merupakan tahap persiapan.

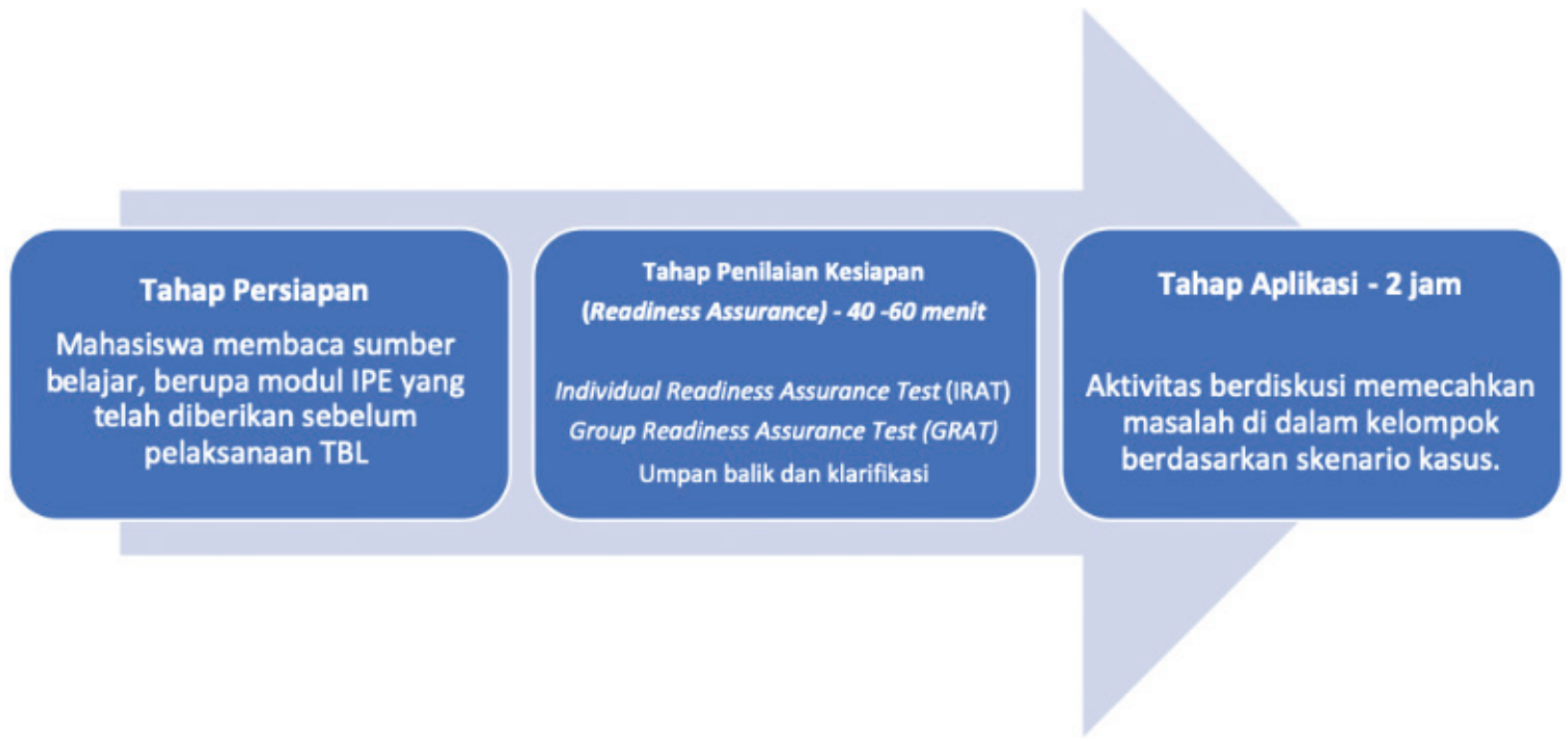

Gambar 1. Proses IPE dengan TBL

Kemudian pada hari H pelaksanaan TBL, mahasiswa akan masuk ke dalam kelas besar dan mereka dibagi ke dalam 26 kelompok kecil yang terdiri dari $6-7$ orang dari empat profesi yang berbeda. Setelah itu mereka menjalani tahap kedua yakni tahapan Readiness Assurance Test (RAT) berupa individual readiness assurance test (IRAT), group readiness assurance test (GRAT) serta umpan balik dan klarifikasi. Pertanyaan pada RAT yang diberikan berupa 10 soal pilihan ganda terkait materi yang sudah dibaca pada modul IPE. Sesi IRAT dilakukan sekitar 10 menit, mahasiswa mengerjakan secara individu, kemudian lembar jawaban IRAT akan dikumpulkan. Lalu dilanjutkan dengan sesi GRAT, dimana mahasiswa mengerjakan soal yang sama dengan sesi IRAT, namun mereka dapat berdiskusi dengan teman sekelompoknya untuk mencari jawaban yang dianggap benar. Sesi GRAT ini menggunakan lembar gores dimana jawaban yang benar bertanda bintang ditutupi dengan stiker gores. Ketika mahasiswa sudah berdiskusi dan mencapai kesepakatan jawaban, mereka akan menggores kertas huruf jawaban tersebut. Jika jawaban yang disepakati masih belum tepat, mereka akan kembali berdiskusi untuk mencari jawaban yang benar sebelum mereka menggores kertas jawaban kembali. Proses GRAT ini 
dapat berlangsung selama kurang lebih 20-30 menit. Setelah GRAT, dilanjutkan dengan proses umpan balik dan klarifikasi dari fasilitator. Pada sesi umpan balik dan klarifikasi, fasilitator akan berdiskusi dengan mahasiswa dan menjelaskan jawaban benar dari setiap pertanyaan pada sesi RAT.

Setelah itu tahap ketiga adalah tahap aplikasi. Pada tahap ini merupakan aktivitas memecahkan masalah menggunakan skenario klinis terkait materi yang sudah dipelajari pada tahap RAT. Mahasiswa diminta untuk dapat berdiskusi dalam kelompoknya mengenai jawaban yang tepat dari setiap skenario tersebut. Soal skenario yang disiapkan berkisar antara $5-8$ soal. Setiap kelompok mahasiswa akan diberikan satu set kertas jawaban yang terdiri dari huruf A sampai E. Ketika mahasiswa sudah berdiskusi dan menentukan jawaban yang disepakati, perwakilan mahasiswa setiap kelompok akan mengangkat kertas huruf jawaban tersebut. Fasilitator akan meminta perwakilan mahasiswa dari satu kelompok untuk dapat menjelaskan kepada kelompok lain alasan mereka memilih jawabannya. Lalu fasilitator akan meminta perwakilan mahasiswa dari kelompok lain untuk menanggapi. Hal ini membuat terjadinya proses diskusi antar kelompok yang berbeda. Kemudian setelah proses diskusi, fasilitator akan memberi umpan balik dan klarifikasi jawaban yang benar. Tahap aplikasi berlangsung selama kurang lebih 2 jam.

Di akhir sesi TBL dilakukan survey menggunakan aplikasi berbasis web, yaitu sli.do. Pertanyaan yang diajukan menggunakan pertanyaan terbuka untuk mengetahui pendapat mahasiswa mengenai pembelajaran IPE dengan menggunakan metode TBL, masukan pembelajaran IPE dengan metode TBL di masa yang akan datang dan juga mahasiswa diminta menilai menggunakan rating mengenai pengalaman belajar yang mereka rasakan.

Hasil darisurvey tersebut kemudian dilakukan analisis tematik. Tahapan dalam melakukan analisis tematik antara lain, pertama peneliti membaca seluruh data yang didapat dari sli.do dan memberi catatan pada kalimat-kalimat yang didapat. Lalu dilakukan skema koding yang dilanjutkan dengan peneliti melihat secara lebih mendetail dan mengidentifikasi tema yang muncul. Kemudian didapatkan tema utama yang merangkum seluruh pendapat dari data yang ada. Penelitian ini telah mendapat persetujuan dari Komite Etik Penelitian Politeknik Kesehatan Tanjungkarang dengan nomor 220/EA/KEPK-TJK/ VII/2019.

\section{HASIL DAN PEMBAHASAN}

Setelah sesi TBL, mahasiswa diberi dua pertanyaan terbuka melalui sli.do secara anonim, yakni "Bagaimana pendapat Anda mengenai pembelajaran IPE dengan metode TBL?" serta "Apa masukan Anda untuk perbaikan pembelajaran IPE dengan metode TBL di masa yang akan datang?".

Pertanyaan pertama mengenai pendapat mahasiswa terhadap proses pembelajaran IPE dengan metode TBL didapatkan 158 peserta yang memberikan pendapatnya melalui sli.do. Sebagian besar peserta berpendapat pembelajaran ini menyenangkan, menambah pengetahuan, meningkatkan kerjasama tim serta komunikasi antarprofesi dan mengembangkan kemampuan berpikir kritis.

\footnotetext{
"Mahasiswa mendapat pembelajaran yang memiliki karakteristik, seperti pengembangan keterampilan pemikiran kritis dari permasalahan yang dibahas, mahasiswa dapat menuangkan pengetahuan yang diketahui di dalam tim, memberi saran, menerima saran, dan menghargai pendapat, mahasiswa belajar dalam bekerja tim, kelompok, mahasiswa merasa menyenangkan" (M33)

"Menyenangkan dan saling memberi saran dan bertukar pikiran sesuai profesi masing masing” (M36)

"Sangat baik karena banyak manfaat mulai dari saling mengenal, saling menghargai pendapat, bagimana saling memahami kewenangan dari masingmasing profesi dan bagaimana saling bekerjasama dalam penyelesaian kasus" (M54)

"Menurut saya cukup efektif karena bisa membuat seluruh anggota kelompok berdiskusi mengemukakan pendapat sesuai profesinya" (M104)
}

Namun ada juga pendapat yang menyatakan bahwa proses tersebut melelahkan dan sedikit membosankan. 
"Melelahkan tapi asik" (M3)

"Metodenya bagus, lumayan menarik dan bisa membuat saya mengerti, dan agak bosan dengan mengisi lembar penilaiannya ke kelompok" (M64)

"Membosankan karena sampai sore" (M81)

Pendapat mahasiswa mengenai pembelajaran IPE dengan metode TBL dapat dilihat pada Tabel 1 .

Tabel 1. Pendapat Mahasiswa mengenai IPE dengan Metode TBL

\begin{tabular}{|c|c|c|}
\hline Pertanyaan & Pendapat & $\begin{array}{c}\text { Frekuensi } \\
\text { Kemunculan }\end{array}$ \\
\hline \multirow{7}{*}{$\begin{array}{l}\text { Bagaimana } \\
\text { pendapat } \\
\text { Anda } \\
\text { mengenai } \\
\text { pembelajaran } \\
\text { IPE dengan } \\
\text { metode TBL? }\end{array}$} & Menyenangkan & 109 \\
\hline & Menambah wawasan & 14 \\
\hline & $\begin{array}{l}\text { Meningkatkan } \\
\text { kerjasama antar profesi }\end{array}$ & 11 \\
\hline & $\begin{array}{l}\text { Berkomunikasi } \\
\text { antarprofesi }\end{array}$ & 22 \\
\hline & $\begin{array}{l}\text { Pengalaman belajar } \\
\text { berbeda }\end{array}$ & 9 \\
\hline & Melelahkan & 4 \\
\hline & Agak bosan & 7 \\
\hline
\end{tabular}

Lalu untuk pertanyaan kedua, ada 159 peserta yang memberi masukannya untuk perbaikan pembelajaran IPE dengan metode TBL di masa yang akan datang. Sebagian besar peserta berpendapat agar dosen yang memberi materi dapat membangun suasana belajar yang lebih menyenangkan, profesi yang dilibatkan dalam pembelajaran IPE lebih banyak, waktu yang digunakan tidak terlalu lama dan masalah yang dibahas lebih banyak dan lebih kompleks.

"Sebaiknya masalah yang dibahas lebih banyak lagi dan lebih rumit lagi, dan profesi yang dilibatkan lebih banyak lagi serta dosen pengajar yang lebih kreatif lagi dalam membangun suasana pembelajaran" (M14)

"Lebih diberikan sedikit permainan atau game selama pembelajaran berlangsung, sehingga pembelajaran tidak berjalan dengan membosankan, waktu yang digunakan tidak terlalu lama sehingga ilmu yang didapat lebih mudah dipahami" (M28)
"Lebih sering lagi dilakukan dan ditambah lagi profesi lain yang diikutkan dalam kegiatan IPE ini" (M67)

Masukan mahasiswa untuk pembelajaran IPE dengan metode TBL di masa yang akan datang dapat dilihat pada Tabel 2 .

Tabel 2. Masukan Mahasiswa mengenai IPE dengan Metode TBL Berikutnya

Pertanyaan $\quad$ Masukan $\quad \begin{gathered}\text { Frekuensi } \\ \text { Kemunculan }\end{gathered}$

Dosen dapat membuat suasana belajar lebih

Apa masukan menyenangkan

Anda untuk

perbaikan

Profesi yang dilibatkan

pembelajaran lebih banyak

IPE dengan Waktu yang tidak

metode TBL terlalu lama

di masa yang Masalah yang dibahas

akan datang? lebih kompleks

Sarana dan prasarana

Hasil survey berdasarkan rating mengenai persepsi mahasiswa terhadap pembelajaran IPE dengan rancangan TBL di Poltekkes Tanjungkarang dapat dilihat pada Gambar 2 berikut:

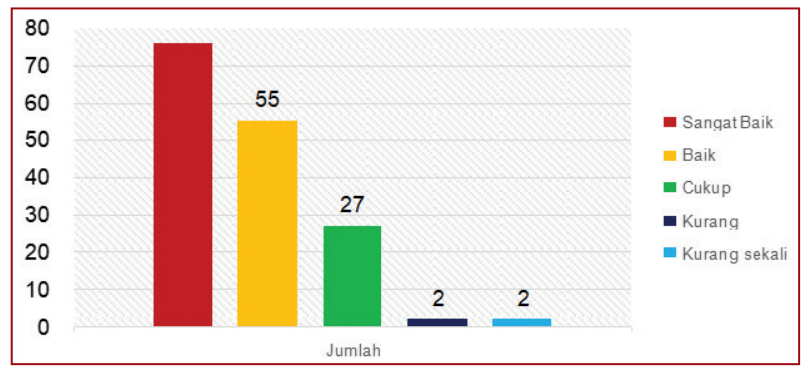

Gambar 2. Persepsi Penerapan Metode TBL pada Pembelajaran IPE Mahasiswa Program Sarjana Terapan Poltekkes Tanjungkarang Tahun 2019

Hasil survey terhadap 162 mahasiswa mengenai penerapan metode TBL pada pembelajaran IPE menunjukkan bahwa 47\% mahasiswa (76 orang) menilai sangat baik, 34\% menilai baik (55 orang), $17 \%$ menilai cukup (27 orang), $1 \%$ menilai kurang ( 2 orang), dan 1\% menilai sangat kurang ( 2 orang). 
Hasil ini menggambarkan bahwa sebagian besar (81\%) mahasiswa menilai rancangan TBL pada pembelajaran IPE positif (sangat baik dan baik) untuk diterapkan di Poltekkes Tanjungkarang.

Berdasarkan hasil penelitian, didapatkan bahwa mahasiswa merasa pembelajaran IPE dengan metode TBL memberikan pengalaman belajar yang berbeda karena mahasiswa dapat belajar dan berdiskusi dengan mahasiswa dari profesi lain dalam satu kelompok sehingga hal ini dapat menambah wawasan mereka. Selain itu pembelajaran IPE dengan TBL meningkatkan kerjasama tim dan komunikasi antar profesi dalam satu kelompok. Hal ini dapat terlihat pada tahap GRAT dan tahap aplikasi. Mahasiswa harus berdiskusi dalam kelompoknya untuk mencapai konsensus jawaban yang disepakati bersama. Semua anggota dalam kelompok berusaha untuk memberikan pendapat sesuai pengetahuannya masing-masing agar kelompoknya dapat menjawab dengan benar. Selain itu, ketika skenario pada tahap aplikasi menyinggung peran dari suatu profesi, peserta didik dari profesi lain akan bertanya dan mendengarkan penjelasan dari teman kelompoknya yang berasal dari profesi lain. Situasi ini mendorong terjadinya komunikasi antar profesi, mahasiswa berusaha untuk saling memahami, menghargai peran dan pengalaman profesi lain.

Pembelajaran IPE yang dilakukan dengan metode TBL memberikan pengalaman belajar yang menyenangkan bagi peserta didik. Peserta didik dari berbagai profesi dipertemukan dalam satu kelompok, bekerja bersama-sama untuk mendiskusikan suatu masalah memberikan pengalaman yang berbeda. Aktivitas mencari jawaban yang benar dengan menggores kertas jawaban pada tahap GRAT membuat suasana pembelajaran lebih seru dan menyenangkan. Peserta didik akan berseru kecewa jika jawaban yang disepakati masih salah dan akan berseru kegirangan ketika mereka berhasil menemukan jawaban yang benar. Melalui proses ini sudah terjadi proses kolaborasi, komunikasi dan kerjasama antar profesi di dalam kelompok. Pada tahap aplikasi, peserta didik dalam kelompok akan berdiskusi secara lebih mendalam dalam tim untuk mencapai keputusan jawaban yang disepakati bersama mengenai skenario kasus yang disajikan.
Kemudian fasilitator akan mendorong terjadinya diskusi antara kelompok satu dengan yang lain. Hal ini membuat peserta didik akan berusaha memberikan performa terbaik untuk kelompoknya. Tahapan ini merupakan kesempatan bagi peserta didik untuk saling membantu temannya agar dapat memahami konsep yang sulit dan mendapatkan perspektif pengetahuan yang baru. Peserta didik akan mempraktikkan kemampuan mendengar aktif, berpikir kritis, menghargai perspektif profesi kesehatan lain sebelum mereka mencapai keputusan jawaban yang disepakati bersama.

Hal tersebut sesuai dengan tujuan pembelajaran IPE yakni diharapkan mahasiswa dapat memahami, menghormati peran dan pengalaman profesi lain dalam mendiskusikan suatu masalah dalam tim. Selain itu melalui metode TBL, mahasiswa juga menunjukkan kemampuan untuk berkolaborasi membangun kerjasama dan komunikasi antar profesi untuk mencapai keberhasilan tujuan tim. ${ }^{12}$

Rancangan TBL sesuai untuk diterapkan pada pembelajaran IPE, karena setiap mahasiswa dari profesi yang berbeda bertanggung jawab atas kemampuan belajar mereka, yang dibagi antara tugas individu dan grup. Ketika TBL sepenuhnya diterapkan, sebagian besar peserta didik disiapkan, datang ke kelas, dan terlibat satu sama lain dengan cara yang produktif saat mereka bekerja sama. Penerapan prinsip pembelajaran orang dewasa pada TBL juga menekankan mahasiswa agar dapat melatih komunikasi, kerjasama/kolaboratif, reflektif dan kepekaan sosial yang dihasilkan selama berinteraksi. Sementara dosen lebih banyak berperan sebagai fasilitator, yang memberikan umpan balik dan penguatan kepada mahasiswa. ${ }^{10-11}$

Salah satu kunci keberhasilan TBL adalah saat membagi anggota kelompok perlu memperhatikan gabungan karakteristik mahasiswa, termasuk jenis kelamin, etnis, grup pertemanan dan juga latar belakang profesi. Ketika anggota kelompok membawa perspektif yang berbeda untuk menyelesaikan tugas yang diberikan, akan terjadi suatu proses kolaborasi menarik untuk mencapai konsensus bersama. ${ }^{7} \mathrm{Hal}$ ini sesuai dengan nilai IPE yang ingin diajarkan kepada peserta didik dimana peserta didik belajar 
untuk bekerja sama, berkomunikasi, dan menghargai pendapat profesi lain.

Pelaksanaan proses pembelajaran TBL memang membutuhkan waktu yang cukup lama, sekitar 2-3 jam. Hal ini dikarenakan setiap anggota kelompok membutuhkan waktu untuk dapat mengenali dinamika kelompoknya sebelum akhirnya terbentuk kelompok yang memiliki performa baik. Oleh karena itu, peserta didik diharapkan dapat berada dalam satu kelompok yang sama sepanjang proses pembelajaran agar terjadi hubungan yang kohesif dan terjadi pembelajaran kelompok yang baik. Hal lain yang perlu diperhatikan juga adalah saat merancang tugas yang harus didiskusikan dalam tim. Pengelola modul harus dapat merancang tugas kelompok yang mendorong terjadinya proses pembelajaran yang membutuhkan interaksi di antara anggota kelompok yang berasal dari profesi yang berbeda-beda. Tugas kelompok harus dapat menghasilkan interaksi tingkat tinggi yang mengharuskan kelompok menggunakan pengetahuan yang sudah dimiliki dari masing-masing profesinya untuk membuat keputusan dalam membahas serangkaian masalah yang kompleks dan memungkinkan kelompok untuk melaporkan keputusan mereka dalam bentuk sederhana. Ketika tugas dirancang untuk membuat keputusan, sebagian besar peserta didik memilih untuk menyelesaikan tugas dengan berdiskusi satu sama lain untuk memecahkan masalah yang diberikan. Sebaliknya, tugas yang menghasilkan output yang kompleks seperti dokumen yang panjang sering membatasi pembelajaran dan pengembangan tim karena biasanya menghambat terjadinya diskusi dua arah sehingga dapat terjadi kebosanan dan tujuan pembelajaran untuk berkolaborasi tidak tercapai. ${ }^{7}$

Staf pengajar sebagai instruktur memegang peranan penting dalam proses keberhasilan pembelajaran IPE dengan menggunakan TBL. Staf pengajar perlu menciptakan suatu konteks pembelajaran yang mendorong, baik secara kuantitas ataupun kualitas, interaksi dalam kelompok yang terdiri dari berbagai profesi agar dapat bertransformasi menjadi kelompok yang memberikan performa secara efektif. ${ }^{7}$ Oleh karena itu diperlukan suatu kegiatan pengembangan yang melibatkan staf pengajar agar mereka dapat memahami bagaimana seharusnya proses TBL dijalankan dengan memperhatikan materi IPE yang ingin disampaikan.

Literatur menunjukkan bahwa pengalaman IPE yang dilakukan sejak tahap awal pendidikan dapat meningkatkan kesiapan mahasiswa untuk pembelajaran IPE dan kerjasama multidisiplin di masa yang akan datang. ${ }^{8}$ Staf pengajar dan institusi pendidikan direkomendasikan untuk mulai mengembangkan suatu model pembelajaran IPE yang disepakati bersama, didukung oleh fasilitas, kebijakan dan peraturan yang jelas. Pembelajaran IPE lebih difokuskan kepada pembelajaran yang lebih menekankan pada proses dan berfokus kepada mahasiswa. ${ }^{4}$

Penelitian ini memberikan awal yang baik untuk menambah informasi mengenai metode pembelajaran interprofesi yang dapat dilakukan di dalam kelas menggunakan Team-Based Learning (TBL). Pengumpulan data menggunakan aplikasi berbasis web sli.do dapat menjadi alternatif teknologi interaktif untuk mengetahui persepsi audiens secara langsung di dalam kelas sehingga dapat memberi umpan balik kepada pengelola program. Namun metode pengumpulan data dengan menggunakan sli. do membuat peneliti tidak dapat menggali lebih lanjut mengenai persepsi mahasiswa dan juga tidak dapat melakukan member-checking karena audiens membuat dirinya anonim. Walau penelitian ini memberi informasi awal yang baik, namun di masa yang akan datang dapat dilakukan metode pengumpulan data seperti focus group discussion ataupun in-depth interview agar dapat mengeksplorasi persepsi secara lebih mendalam, serta perlu dilakukan metode validasi data lain seperti triangulasi atapun member-checking. Selain itu, pertanyaan yang menggunakan skala rating untuk menilai pelaksanaan IPE dengan metode TBL masih dapat dielaborasi lagi karena dalam penelitian ini hanya mengajukan satu pertanyaan untuk mengetahui pendapat mahasiswa mengenai pengalaman belajar IPE menggunakan TBL.

\section{KESIMPULAN}

Persepsi mahasiswa terhadap pembelajaran IPE yang dilakukan dengan metode TBL antara lain 
proses pembelajaran menyenangkan, menambah pengetahuan, meningkatkan kerjasama tim serta komunikasi antarprofesi dan mengembangkan kemampuan berpikir kritis. Adapun masukan untuk pelaksanaan IPE dengan metode TBL di masa yang akan datang antara lain dosen yang memberi materi dapat membangun suasana belajar yang lebih menyenangkan, profesi yang dilibatkan dalam pembelajaran IPElebih banyak, waktu yang digunakan tidak terlalu lama dan masalah yang dibahas lebih banyak dan lebih kompleks. Didapatkan hasil 81\% mahasiswa memiliki respon positif (sangat baik dan baik) mengenai pembelajaran IPE dengan metode TBL. Metode TBL dapat menjadi salah satu alternatif metode pembelajaran untuk menyampaikan materi dan konsep dari IPE.

\section{SARAN}

Penerapan metode pembelajaran TBL untuk IPE memerlukan persiapan yang matang baik dari segi dosen, tenaga kependidikan, sarana dan prasarana agar dapat menciptakan pengalaman belajar kolaboratif yang menyenangkan bagi peserta didik. Perlu eksplorasi secara mendalam mengenai persepsi mahasiswa dan dosen mengenai pelaksanaan IPE dengan metode TBL.

\section{UCAPAN TERIMA KASIH}

Penulis mengucapkan terima kasih kepada Direktur Poltekkes Tanjungkarang, Dekan Fakultas Kedokteran dan semua civitas akademika Poltekkes Tanjungkarang yang telah bekerja sama untuk melaksanakan proses pembelajaran IPE menggunakan metode TBL.

\section{DEKLARASI KEPENTINGAN}

Penulis tidak memiliki konflik kepentingan apapun terkait studi pada naskah ini.

\section{KONTRIBUSI PENULIS}

Warjidin Aliyanto - menulis proposal penelitian, analisis data dan publikasi manuskrip

Retno Puji Hastuti - menulis proposal penelitian, mengumpulkan dan analisis data
Dwita Oktaria - mengumpulkan dan analisis data serta publikasi manuskrip

\section{DAFTAR PUSTAKA}

1. Susilaningsih FS, Mukhlas M, Sunartini, Utarini A. Nurse-physician collaborative practice in interdisiplinary model of patient care. Jurnal Manajemen Pelayanan Kesehatan. 2011 Jun 2; 14. https://jurnal.ugm.ac.id/jmpk/article/ view/2593

2. Lestari E, Stalmeijer RE, Widyandana D. Scherpbier A. Understanding student' readiness for interprofessional learning in an Asian context: a mixed-methods study. BMC Med Educ. 2016 Jul 15; 16:179 DOI 10.1186/s12909016-0704-3. Online dari https://www.ncbi.nlm. nih.gov/mc/articles/PMC4946087.

3. WHO. Human Resources for Health Framework for Action on Interprofessional Education \& Collaborative Practice. World Health Organization, WHO/HRH/HP. 2010; 1-64. Retrieved from http://www.who.int/ $\mathrm{hrh} /$ resources/framework_action/en/

4. Fuadah DZ, Hapsara S, Sedyowinarso M. The readiness of students to learn interprofessional teamwork in antenatal care. Jurnal Ners; 20169 (2): 226. https://doi.org/10.20473/ jn.V9I11014.226-235

5. Pusdik BPPSDM Kemenkes RI. Pedoman Implementasi Pendidikan Antar Profesi (Interprofesional Education). 2016. Jakarta: BPSDM Kemenkes RI

6. Barr H. Toward a theoretical framework for interprofessional education. Journal of Interprofessional Care. 2013; 27(1), 4-9. https:// doi.org/10.3109/13561820.2012.698328

7. Michaelsen LK, Sweet M. The essential elements of Team-Based Learning. 2008. (116), 1-18. https://doi.org/10.1002/tl

8. Burgess A, Kalman E, Haq I, Leaver A, Roberts $\mathrm{C}$, Bleasel J. Interprofessional team-based learning (TBL): how do students engage? BMC Medical Education. 2020; 20:118. https://doi. org/10.1186/s12909-020-02024-5 
9. Burgess A, Diggele CV, Matar E. 11. Parmelee DX, Michaelsen LK. Twelve tips Interprofessional team-based learning: building social capital. Journal of Medical Education and Curricular Development. 2020; 7;1-7. https:// doi.org/10.1177/2382120520941820

10. Gilbert JHV, Yan J, Hoffman SJ. A WHO report: Framework for action on interprofessional education and collaborative practice. Journal of Allied Health, 2010; 39(SUPPL. 1), 196-197. for doing effective Team-Based Learning (TBL). Med Teach. 2010; 32: 118-122. doi: 10.3109/01421590903548562. PMID: 20163226.

12. Hean S, Craddock D, Hammick M, Hammick M. Theoretical insights into interprofessional education: AMEE Guide no. 62. Med Teach. 2012; 34: e78-e101. 